ISSN = 1980-993X - doi:10.4136/1980-993X
www.agro.unitau.br/ambi-agua
E-mail: ambi-agua@agro.unitau.br
Tel.: (12) 3625-4116

\title{
Fragilidade ambiental e uso do solo da bacia hidrográfica do Córrego Pindaíba, Uberlândia, MG, Brasil (doi:10.4136/ambi-agua.42)
}

\author{
Paula Cristina Almeida de Oliveira ${ }^{1}$; Gelze Serrat de Souza Campos Rodrigues ${ }^{2}$; \\ Silvio Carlos Rodrigues ${ }^{3}$ \\ ${ }^{1}$ Mestranda - Bolsista CNPq - Universidade Federal de Uberlândia \\ E-mail: paulinhageo@yahoo.com.br \\ ${ }^{2}$ Doutora em Geografia - Fundação Estadual do Meio Ambiente \\ E-mail: gelcampos@ig.ufu.br \\ ${ }^{3}$ Prof. Dr. Universidade Federal de Uberlândia. Avenida João Naves de Ávila, 2121, sala 1 H16. \\ CEP: 38.408-100 - Uberlândia, MG \\ E-mail: silgel@ufu.br
}

\section{RESUMO}

Este trabalho estudou a fragilidade ambiental na bacia hidrográfica do córrego Pindaíba por meio da análise das interações dos componentes naturais e antrópicos existentes na área estudada. O objetivo principal desta pesquisa foi identificar e mapear a fragilidade ambiental existente na bacia hidrográfica do Córrego Pindaíba. Os objetivos específicos consistiram na caracterização física e no uso e ocupação do solo da referida bacia hidrográfica. Para a realização da pesquisa foram feitos vários trabalhos de campo em toda a extensão da bacia. Para a confecção da base cartográfica foram utilizadas as cartas topográficas de Taboca e Pau-Furado na escala de 1:25.000. Posteriormente, a base foi vetorizada no software Cartalinx. Os mapas temáticos de geologia, geomorfologia e do uso do solo foram compilados com base no software Arcview 3.2. O mapa de fragilidade também foi criado no software Arcview 3.2, utilizando-se o módulo Geoprocessing Wizard. Para a avaliação da fragilidade do relevo, aplicada ao planejamento ambiental, utilizou-se a metodologia de Ross (1990, 1994) que atribui valores às variáveis do meio ambiente de acordo com suas potencialidades. Como resultado, obteve-se a identificação das principais ações naturais e antrópicas atuantes na bacia e um mapa com as áreas de fragilidade da bacia. Esses resultados indicam que devem ser feitas alterações no uso da terra, adequando-se os tipos de cultura à morfologia da área, levando-se em consideração não só os recursos naturais, mas também as necessidades de seus moradores.

Palavras-chave: Fragilidade ambiental; bacia hidrográfica; planejamento ambiental.

\section{Environmental fragility and land use of the Pindaíba Creek Hydrographic Basin, Uberlândia, MG, Brazil}

\section{ABSTRACT}

This paper presents an environmental analysis of the fragility of Pindaíba Creek Hydrographic Basin using the analysis of natural and anthropic components interactions in the study area. The main objective of this research was to identify and map the environmental fragility of this basin. The specific objectives consisted in the physical characterization of land use and land cover. To accomplish this research, several field campaigns were conducted throughout the basin. The cartographic base was compiled using the Taboca and Pau Furado charts at 1:25.000 scale that were digitized using the software Cartalinx. The thematic maps 
of geology, geomorphology, and land use were compiled using the software Arcview 3.2. The fragility map was also derived based on the software Arcview 3.2 using the tool Geoprocessing Wizard. The methodology developed by Ross $(1990,1994)$ was used for the evaluation of the landscape fragility. This methodology attributes values to environment variables according to their potentialities. Results allowed the identification of major natural and anthropic actions in the study area represented in a map of fragility potential. These results indicate that land use has to be changed in order to adjust to the landscape morphology, considering not only natural resources, but also the needs of the people who live in the study area.

Keywords: environmental fragility; hydrographic basin; environmental planning.

\section{INTRODUÇÃO}

Ao longo da história, o homem evoluiu, acumulando conhecimentos; suas necessidades básicas e curiosidades estimularam o interesse por novas descobertas, por melhor conhecer a si próprio, bem como o universo que o cerca. Entretanto, essa evolução de conhecimentos e aprendizados não trouxe apenas resultados positivos, pois as alterações propiciadas pela aplicação desses novos conhecimentos trouxeram reflexos sobre a forma de funcionamento dos processos naturais.

O meio ambiente tornou-se uma das grandes preocupações da humanidade, que busca aliar a evolução de suas tecnologias com preservação do meio ambiente, visto que a intensidade das ações antrópicas sobre o meio físico acelera a velocidade dos processos naturais, alterando seu comportamento.

Na região do Triângulo Mineiro, a paisagem do Cerrado sofreu significativas alterações com a introdução da moderna agricultura, onde a vegetação natural foi quase totalmente substituída por pastagens e culturas agrícolas. Essa agricultura se tornou uma das atividades que causaram os maiores impactos ambientais no Cerrado, principalmente, pelo fato de essas áreas possuírem um relevo com formas pouco dissecadas e suaves, que facilitam a mecanização agrícola. As transformações na dinâmica da paisagem atingiram também as bacias hidrográficas, onde os eventos de origem antrópica interferem diretamente na dinâmica desse sistema, influenciando sua quantidade e qualidade, devido à intensa pressão causada pela utilização desordenada de seus componentes.

A bacia hidrográfica do córrego Pindaíba se localiza próxima à área urbana de Uberlândia e está situada na direção de expansão do município, fazendo parte da bacia hidrográfica do Rio Araguari (Figura 1).

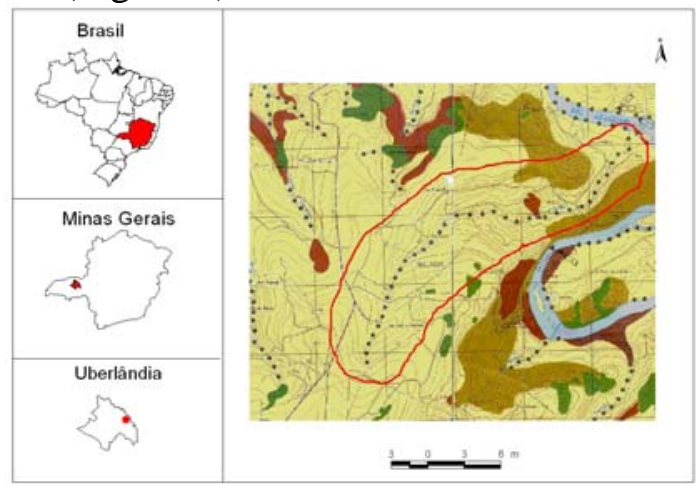

Figura 1. Localização da bacia hidrográfica do córrego Pindaíba. 
A bacia hidrográfica do córrego Pindaíba, além de apresentar uma grande diversidade no uso da terra e dos recursos hídricos, foi afetada parcialmente pela construção do lago da Usina Hidrelétrica Capim Branco I.

A análise geográfica da bacia hidrográfica do córrego Pindaíba torna-se necessária para o entendimento dos processos naturais e suas relações com as atividades antrópicas. Este trabalho justifica-se pela necessidade de compreender a dinâmica natural da referida bacia, tendo em vista os diferentes níveis de intervenção humana nela.

Marques (2001, p.45) diz que "a visão holística da paisagem e a necessidade da compreensão das relações entre o homem, a natureza e a sociedade criaram novas visões e enfoques para as pesquisas ambientais".

As bacias hidrográficas têm se tornado um importante instrumento para o gerenciamento das atividades de uso e conservação dos recursos naturais. Segundo Botelho e Silva (2004, p.184) é consenso entre os pesquisadores que a bacia hidrográfica é o espaço de planejamento e gestão das águas onde se procura compatibilizar as diversidades demográficas, sociais, culturais e econômicas das regiões.

Baccaro et al. (2004) afirmam que a bacia do rio Araguari necessita de um planejamento que vise ao desenvolvimento sustentável das atividades futuras e também ao monitoramento das atividades em andamento.

O objetivo principal desta pesquisa é identificar e mapear a fragilidade ambiental existente na bacia hidrográfica do córrego Pindaíba. Os objetivos específicos consistem na caracterização física e na caracterização do uso e ocupação do solo da referida bacia hidrográfica.

Na elaboração da pesquisa foram consideradas algumas definições relacionadas ao planejamento ambiental, à hidrográfica e à fragilidade ambiental.

Para Santos (2004), o planejamento ambiental surgiu da necessidade da organização do uso da terra em resposta ao aumento da demanda do uso irracional dos recursos energéticos, biológicos, terras e água.

Gomez Orea (1978 apud Botelho, 1995) define planejamento ambiental como sendo "um processo de tomada de decisões que implicam numa reflexão sobre as condições econômicas, sociais e ambientais que orientam qualquer decisão futura".

Já Gallopin (1981 apud Botelho, 1995) define planejamento como uma proposta de implementação de medidas para melhorar a qualidade de vida presente e futura dos seres humanos, pela preservação e do melhoramento do meio ambiente.

Segundo Santos (2004, p.28),o planejamento ambiental fundamenta-se na interação e integração dos sistemas que compõem o ambiente. Tem o papel de estabelecer as relações entre os sistemas ecológicos e os processos da sociedade, das necessidades socioculturais a atividades e interesses econômicos, a fim de manter a máxima integridade possível dos seus elementos componentes.

A bacia hidrográfica ou bacia de drenagem é entendida como uma área da superfície da Terra drenada por um rio principal e seus tributários sendo limitada pelos divisores d’água. (Botelho, 2004).

No Brasil, foi apenas a partir da década de 80 do século passado que se atenuaram os estudos e trabalhos relacionados com a bacia hidrográfica como unidade de planejamento. A bacia de drenagem exerce um importante papel no que se refere à evolução do relevo uma vez que os cursos d'água constituem importantes modeladores da paisagem. (Guerra e Cunha, 1996). 
Nessa perspectiva, planejamento ambiental em bacias hidrográficas torna-se extremamente importante, pois atua como instrumento para minimizar a ação de impactos ambientais decorrentes da ação antrópica.

Para se avaliar o potencial de fragilidade de um determinado ambiente natural é necessário considerar as características genéticas e as atividades antrópicas desenvolvidas nesse ambiente.

Conforme Spörl e Ross (2004, p.40), a identificação dos ambientes naturais e suas fragilidades potenciais e emergentes proporcionam uma melhor definição das diretrizes e ações a serem implementadas no espaço físico territorial, servindo de base para o zoneamento e fornecendo subsídios à gestão do território.

Nesse sentido, Kawakubo et al. (2005, p. 2203) afirmam que:

"O mapa de fragilidade ambiental constitui uma das principais ferramentas utilizadas pelos órgãos públicos na elaboração do planejamento territorial ambiental. O mapeamento da fragilidade ambiental permite avaliar as potencialidades do meio ambiente de forma integrada, compatibilizando suas características naturais com suas restrições."

O mapeamento da fragilidade ambiental em bacias hidrográficas assume um importante papel no que tange ao planejamento territorial, pois orienta o tipo de uso mais adequado, visando à redução dos impactos causados pela ocupação desordenada.

\section{MATERIAIS E MÉTODOS}

Foram realizados vários trabalhos de campo em toda a extensão da bacia, com o objetivo de caracterizá-la, bem como identificar as principais ações naturais e antrópicas.

Para a confecção da base cartográfica foram utilizadas as cartas topográficas de Taboca (SE 22-Z-B-VI-4 NE) e Pau-Furado (SE 22-Z-B-VI-4 NO) na escala de 1:25.000 (IBGE, 1984). Posteriormente, a imagem foi vetorizada no software Cartalinx.

Os mapeamentos temáticos foram derivados de dados secundários elaborados por diversos autores. Como a fonte original era diferente da utilizada neste mapeamento, foram utilizadas as legendas originais com as devidas simplificações devido à necessidade de adaptação ao processo de análise da fragilidade da paisagem. O mapa de geologia foi adaptado do Mapa Geológico do Município de Uberlândia elaborado por Nishiyama (1998) na escala de 1.100.000, o mapa geomorfológico foi adaptado do Mapa Geomorfológico da Bacia do Rio Araguari, realizado por Baccaro et al. (2004). O mapa de uso do solo foi adaptado dos mapas do Plano de Controle Ambiental AHE Capim Branco I (CCBE, 2005).

A confecção dos mapas temáticos foi realizada no software Arcview 3.2. O mapa de fragilidade também foi criado no software Arcview 3.2, utilizando o módulo Geoprocessing Wizard.

Para analisar a fragilidade do relevo, Ross (1990) estabeleceu uma ampliação das concepções de Tricart (1977). Essa nova proposta indica que as unidades ecodinâmicas podem estar em equilíbrio dinâmico ou em desequilíbrio, suprimindo a classificação intergrade proposta por Tricart. Assim, os ambientes são classificados em estáveis, quando estão em equilíbrio dinâmico e classificados em ambientes instáveis, quando estão em desequilíbrio.

Para aplicar a metodologia da fragilidade ao planejamento ambiental, Ross $(1990,1994)$ propõe a classificação dos graus de fragilidade, atribuindo valores a eles, de forma que, quanto maior a classe de fragilidade, maior é o valor atribuído a ela. 


\section{RESULTADOS E DISCUSSÃO}

\subsection{Caracterização física da área de estudo}

Com suas nascentes na Serra da Canastra, a Bacia Hidrográfica do Rio Araguari possui 22.186 km² de área, e abrange o território de 20 municípios de Minas Gerais. O município de Uberlândia situa-se na mesorregião do Triangulo Mineiro e Alto Paranaíba, e segundo dados da Prefeitura Municipal de Uberlândia, de 2006, a população estimada é de 600 mil habitantes, distribuídos em uma área de aproximadamente 4.115 km² (Prefeitura..., 2007).

\subsubsection{Clima}

De acordo com Silva e Assunção (2004), o município de Uberlândia, segundo a classificação de Köppen, está inserido no contexto dos climas do tipo Aw, ou seja, possui inverno seco e verão chuvoso, dominado predominantemente pelos sistemas intertropicais e polares. A temperatura média varia de 19 a $27^{\circ} \mathrm{C}$ e a pluviosidade média fica em torno de $1500 \mathrm{~mm} /$ ano.

\subsubsection{Geologia}

A bacia hidrográfica do córrego Pindaíba apresenta basaltos da Formação Serra Geral, de idade Mesozóica, arenitos da Formação Marília e migmatitos do Embasamento Cristalino (Nishiyama, 1989), de acordo com a Figura 2.

As nascentes estão sobre a Formação Marília. Os basaltos da Formação Serra Geral afloram principalmente às margens do córrego. Essa formação é responsável pelas pequenas corredeiras e quedas d'água existentes ao longo do córrego sendo observado em afloramentos rochosos. Os gnaisses afloram em forma de matacões no médio curso, em uma área de contato com o basalto, e os migmatitos afloram no baixo curso do córrego, em uma área de relevo mais íngreme.

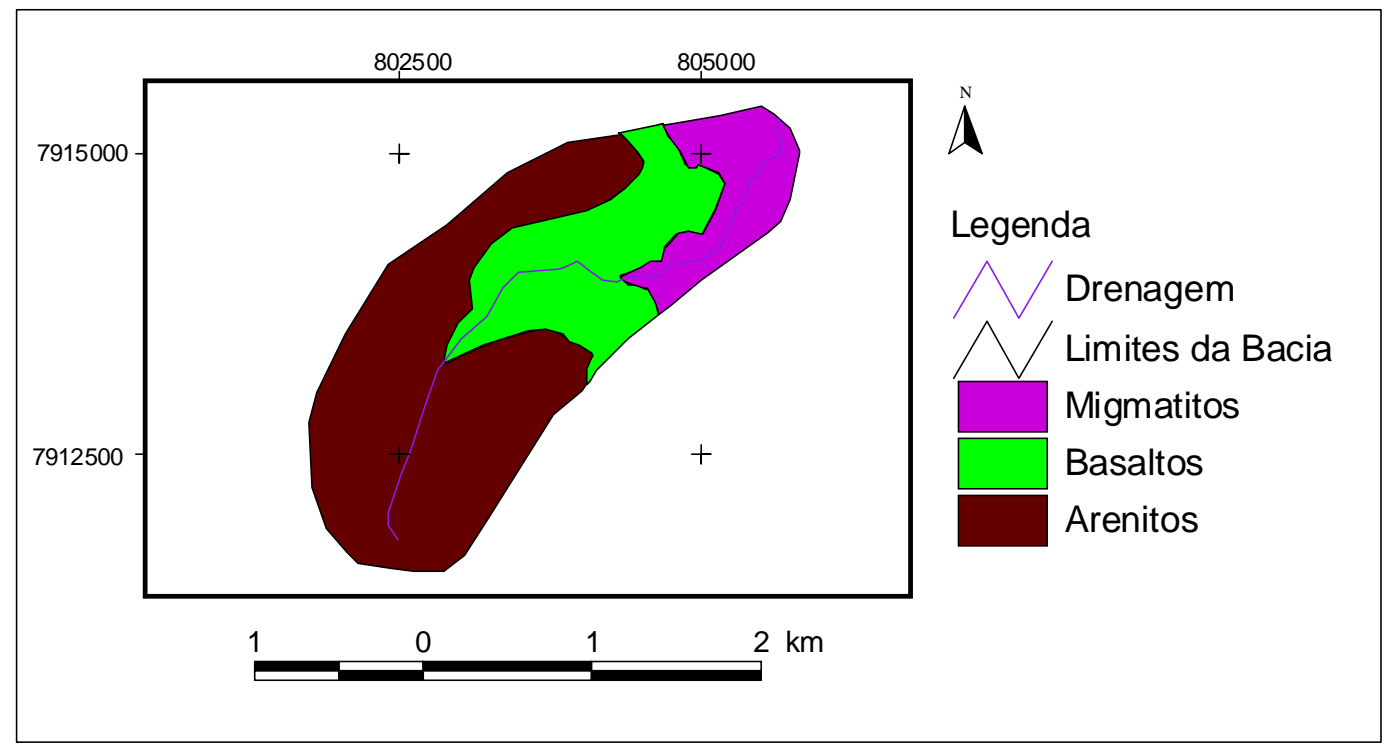

Figura 2. Mapa Geológico da bacia hidrográfica do córrego Pindaíba. Autor: Oliveira (2006).

\subsubsection{Geomorfologia}

Baccaro (1989) afirma que a área do município de Uberlândia está classificada em três categorias: área de relevo dissecado, que corresponde às áreas com topos aplainados entre 700 
e 900 metros, áreas com relevo intensamente dissecado, que apresenta uma porção mais elevada com topos aplainados, pertencentes a uma grande chapada que se estende por toda a região e áreas de relevo com topo plano, que correspondem a uma área de topos planos e largos e vales espaçados entre si com pouca ramificação de drenagem e vertentes entre 3 e $5^{\circ}$ de inclinação.

Segundo a Figura 3, a bacia hidrográfica do córrego Pindaíba está inserida na Unidade Morfoestrutural da Bacia Sedimentar do Paraná, na unidade geomorfológica do Cânion do Araguari, sendo caracterizada como uma área de relevo intensamente dissecado, apresentando vertentes abruptas e forte entalhamento dos vales e relevos bem encaixados.

A unidade Cânion do Araguari apresenta um forte entalhamento dos vales e das vertentes, além de perfis de vertentes com rupturas côncavas, segmentos convexos, paredões rochosos e terraços fluviais.

O córrego Pindaíba não possui afluentes, ele nasce em uma área de patamares planos, num vale amplo, que se torna estreito com presença de cachoeiras e corredeiras, após entrar na área de cânions. Na área de estudo, os terraços são utilizados para produção agrícola, principalmente a banana e hortifrutigranjeiros, e as áreas mais inclinadas são utilizadas para pastagens.

Os sulcos e ravinas estão presentes ao longo de toda a bacia, como também a ocorrência de assoreamento das margens do córrego, principalmente próximo à sua foz (Oliveira, 2006).

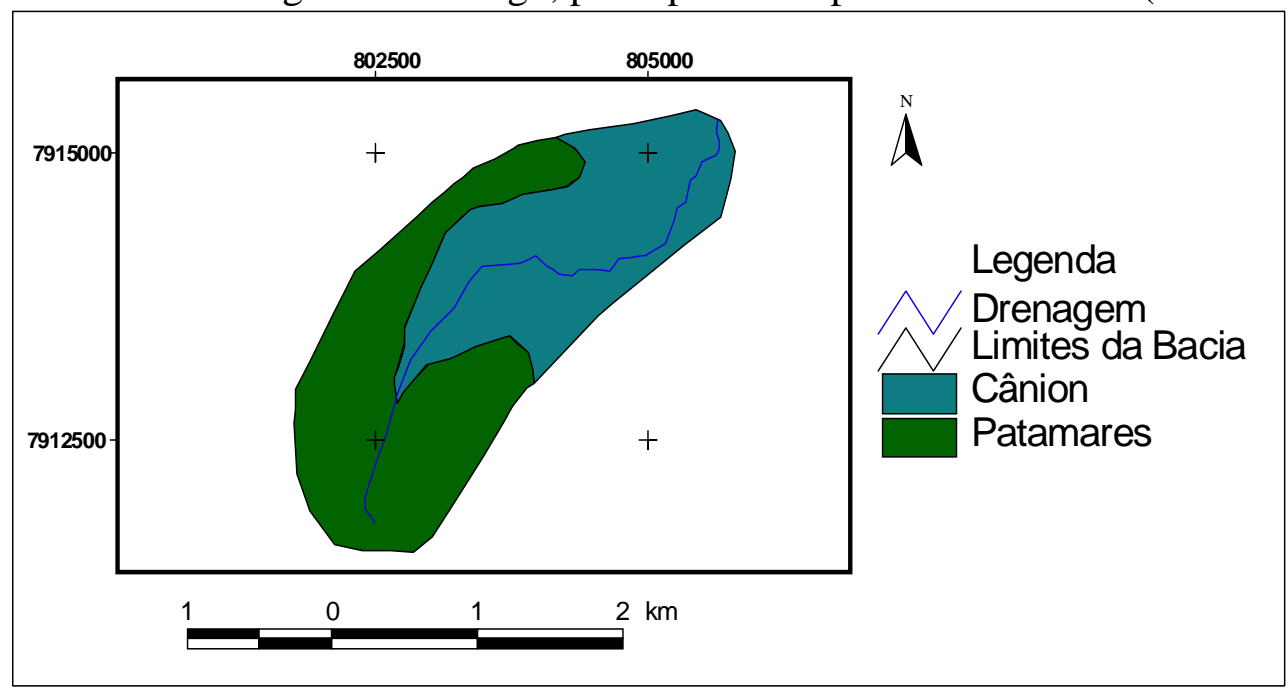

Figura 3. Mapa Geomorfológico da bacia hidrográfica do córrego Pindaíba. Autor: Oliveira (2006).

\subsubsection{Cobertura Vegetal}

A cobertura vegetal do município está inserida nos Domínios Morfoclimáticos dos Cerrados, (Ab’Sáber, 2003) e, segundo Giffoni e Rosa (2007), os principais tipos fisionômicos existentes são mata ciliar ou galeria, cerrado, campo limpo, campo sujo e cerradão.

A cobertura vegetal da bacia do córrego Pindaíba apresenta um estado de avançada degradação. A vegetação típica do Cerrado foi quase totalmente extinta, dando lugar à pastagem e culturas temporárias de hortifrutigranjeiros. Nas margens do córrego, estão presentes, de forma descontínua, espécies de médio e grande porte, da Mata de Galeria e Mata Mesofítica, intercaladas com pastagens e culturas.

Os trechos com vegetação em regeneração e Mata Mesofítica se encontram sob as áreas de cânion. Mais expressivamente nas áreas de patamares se concentram a produção de 
berinjela e quiabo; culturas anuais como banana e cana-de-açúcar e pastagem melhorada, segundo a Figura 4.

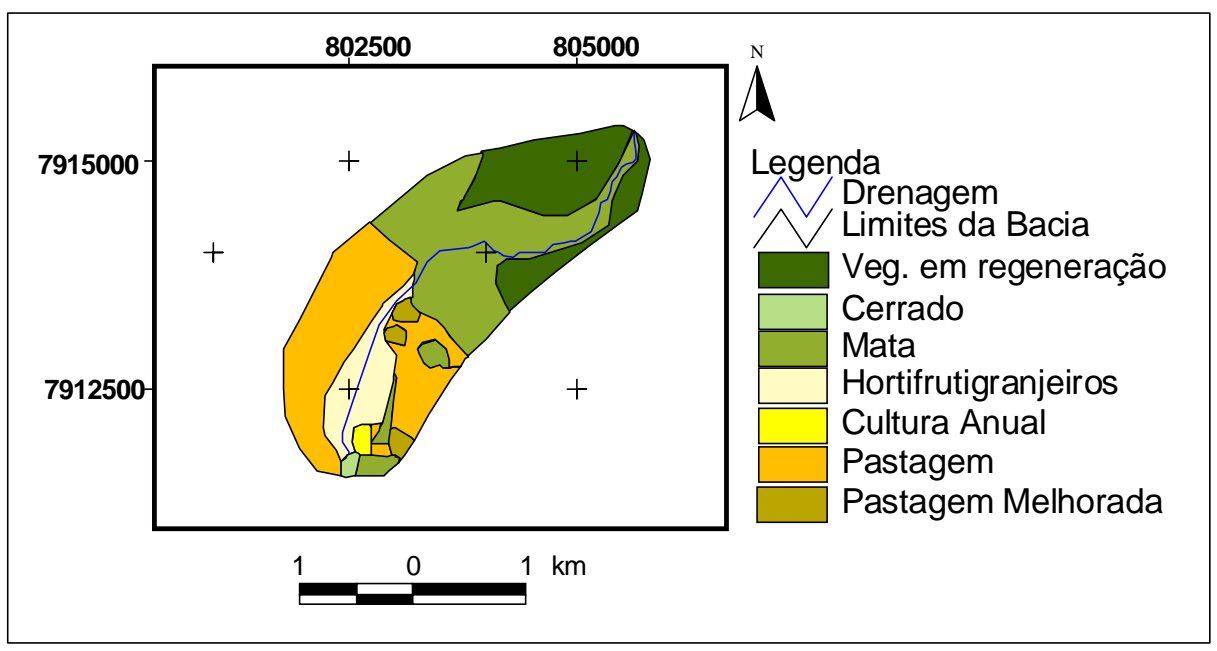

Figura 4. Mapa de Uso e Ocupação da Terra da bacia hidrográfica do córrego Pindaíba.

Fonte: CCBE (2005). Autor: Oliveira (2006).

\subsubsection{Solos}

Os solos existentes no município de Uberlândia são o Latossolo Vermelho-Amarelo (LVa), o Latossolo Vermelho Distrófico (LVd), o Gleissolo (Gxbe), o Argissolo VermelhoAmarelo eutrófico (Pvae) e o Cambissolo (Cxd1) (Embrapa, 1982 apud Atehortúa, 2004).

\subsubsection{Bacia Hidrográfica do Córrego Pindaíba}

A bacia hidrográfica do córrego Pindaíba apresenta níveis de degradação bastante elevados.

A nascente principal do córrego está localizada em área antropizada, situada sob as raízes de uma gameleira, e se encontra parcialmente cercada e coberta por telhas para evitar o pisoteio do gado e de animais de pequeno porte. As nascentes secundárias se formam sob um campo hidromórfico, com vegetação rasteira e resquícios de pastagem e milho, o que significa que a área já foi cultivada.

No geral, a área das nascentes apresenta um estado de degradação avançado. A nascente principal apresenta indícios de culturas de pequeno porte, e o solo apesar de possuir gramíneas nas margens é exposto. A nascente principal foi parcialmente canalizada para abastecer a sede da Fazenda Pindaíba. O campo hidromórfico que abriga as nascentes secundárias também apresenta vestígios de culturas e a vegetação circundante às nascentes é pouco expressiva

Logo após as nascentes, o córrego apresenta um longo trecho de vegetação secundária de médio porte. Ambas as margens são ocupadas por culturas como chuchu, berinjela, quiabo, banana e algumas árvores frutíferas (Figura 5). Nessa propriedade, existe o sistema de rotação de culturas, sendo que a banana é produzida em grande escala. A água é bombeada e consumida pelas atividades da fazenda. Outra atividade desenvolvida nessa propriedade é a criação de gado. 


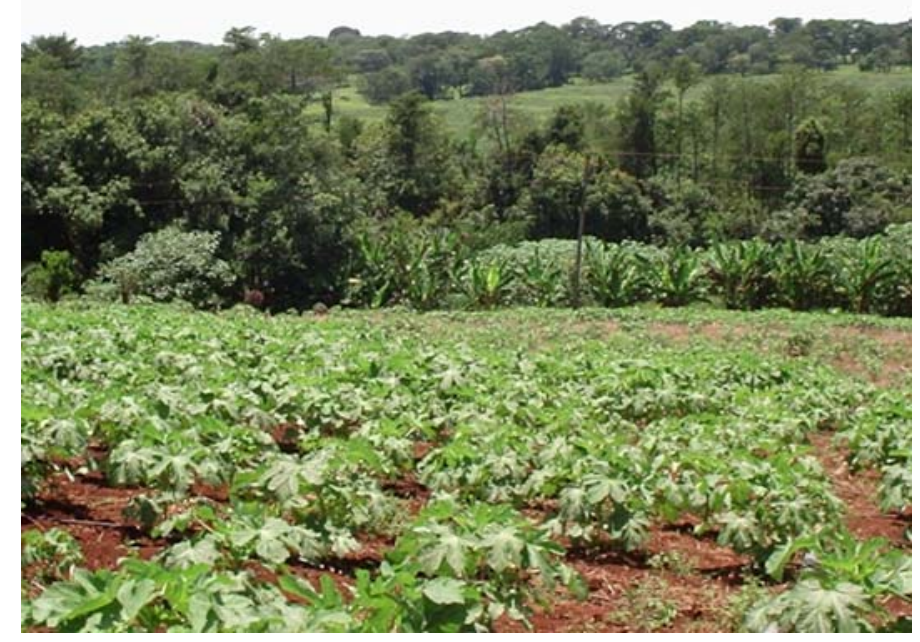

Figura 5. Plantação de quiabo, seguida do bananal em segundo plano e mata ciliar ao fundo.

Autor: Oliveira (2006).

Nas terras da Fazenda Tenda e Laje, o córrego já apresenta um vale fechado e o relevo mais inclinado. A superfície é recoberta por uma escassa camada de serrapilheira e algumas árvores frutíferas. O fato de estar desprotegida favorece a erosão e o transporte de sedimentos para o córrego, provocando assoreamento. Nessa fazenda, o córrego apresenta duas represas artificiais para abastecimento da fazenda e irrigação da lavoura. Na saída de água da primeira represa, o curso do córrego foi desviado e, posteriormente, canalizado, sendo que no curso desviado existe uma cachoeira artificial.

A Fazenda Laje apresenta o trecho do córrego mais protegido. As margens abrigam uma vegetação densa com árvores de médio e grande porte. Os solos são latossolos vermelhos cobertos por serrapilheira. O córrego apresenta trechos com afloramentos de basalto, onde aparecem corredeiras e quedas de pequeno porte, com boa vazão.

Nessa área, o relevo é mais inclinado e o solo é coberto por pastagens, visto que a atividade principal da fazenda é a criação de gado. A água é captada por uma bomba d'água para abastecimento da fazenda. Devido à declividade do terreno e à cobertura vegetal representada por pastagens, em alguns trechos próximos às margens do córrego aparecem alguns pontos com ravinas.

Na divisa entre a Fazenda Laje e a fazenda subseqüente, também denominada Pindaíba, a dinâmica do córrego já foi alterada. Existe um barramento do córrego, formando uma cachoeira artificial feita para a retirada de água com auxilio de uma bomba (Figura 6). A margem esquerda apresenta vegetação de pequeno porte e indícios de pisoteio de gado.

A vegetação ciliar da margem direita foi retirada, dando lugar à pastagem e à plantação de banana. 


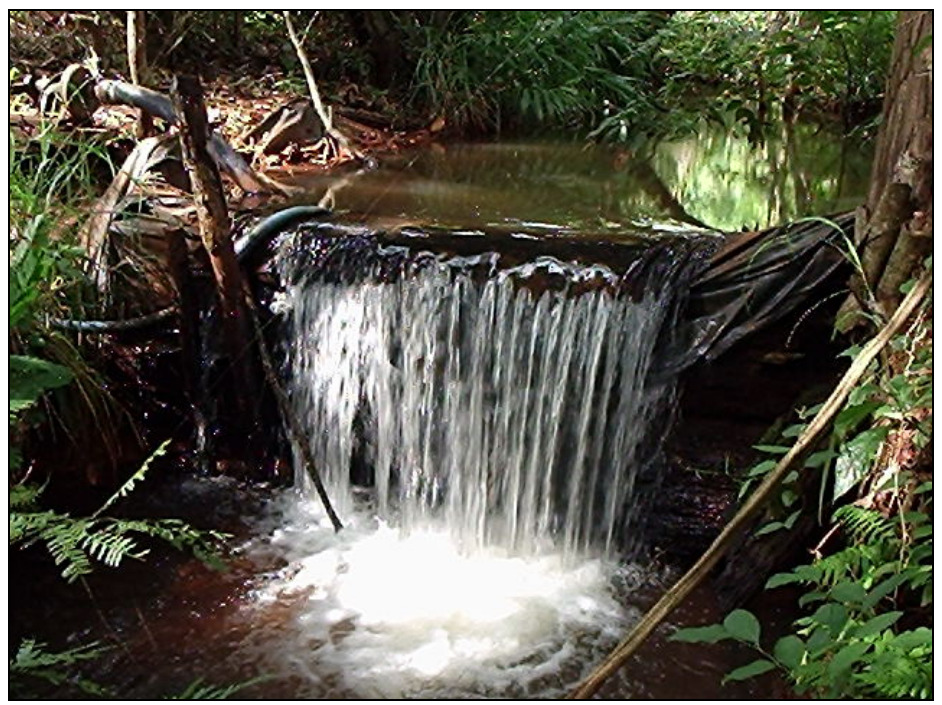

Figura 6. Queda artificial feita para captação de água.

Autor: Oliveira (2006).

A jusante, na Fazenda Nossa Senhora da Abadia, o córrego apresenta vários afloramentos de basalto, e uma queda natural de aproximadamente seis metros de altura. A vegetação ciliar apresenta dossel superior a 10 metros de altura e o córrego se apresenta bastante assoreado e suas margens apresentam indícios de pisoteio de animais. Após a cachoeira, o curso do córrego foi desviado. O curso artificial abastece duas represas, uma para abastecimento e outra destinada à criação de peixes (Figura 7). Posteriormente, o curso desviado se encontra com o canal normal.

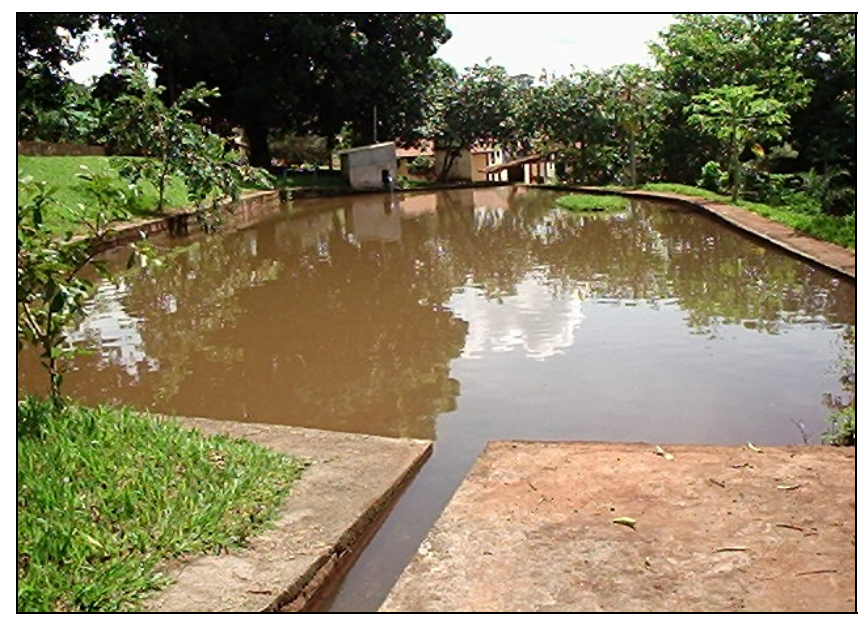

Figura 7. Represamentos formados a partir do curso desviado do córrego.

Autor: Oliveira (2006).

O curso normal do córrego também abastece duas represas, que por sua vez estão bastante assoreadas. Suas margens encontram-se bastante degradadas, com solo exposto e algumas arvores frutíferas na margem esquerda, e vegetação rasteira e solo exposto na margem direita.

No médio curso, na fazenda também denominada Pindaíba, o córrego foi alterado para abastecer duas represas artificiais que são utilizadas para irrigação. A atividade principal nessa propriedade é o cultivo de banana, além de maracujá e chuchu. O relevo é bastante 
inclinado, os solos possuem vegetação rasteira e o córrego apresenta ainda algumas corredeiras e árvores de médio porte e bambuzais. Por se tratar de uma área de contato, apresenta vários afloramentos de basaltos e gnaisses.

No curso inferior, próximo à sua foz, o córrego apresenta o maior nível de degradação. Nesse local, a vegetação natural é bastante escassa, com poucas árvores, onde predominam as pastagens. O relevo se apresenta mais dissecado, com formas convexas, aflorando migmatitos do Embasamento Pré-Cambriano.

A formação do lago da usina hidrelétrica Capim Branco I provocou alterações na dinâmica do córrego. A foz, que se encontrava em elevado grau de degradação, com a vegetação natural substituída por pastagem e erosão nas margens, teve alguns metros submersos pela água do lago. Porém depois da formação do lago, as margens continuam sem a proteção da vegetação natural, cobertas apenas por pastagem. Nas margens do córrego é constante a presença de animais.

\subsection{Fragilidade Ambiental}

Para a determinação das classes de fragilidade ambiental, foram consideradas as variáveis geologia, geomorfologia e uso da terra, em que valores de 1 a 5 foram atribuídos a eles, de acordo com seu grau de proteção (Rodrigues, 2000). Quanto maior a classe de fragilidade, que está diretamente ligada a potencialidade da variável de potencializar processos erosivos, maior é o valor atribuído a ela.

Em relação à geologia, a Formação Serra Geral foi classificada como tendo uma baixa fragilidade, sendo que o valor atribuído a ela foi 1. A Formação Marilia possui valor 2 por ter fragilidade considerada baixa - média. O Embasamento Cristalino possui a fragilidade média, com valor 3.

No que se refere às unidades geomorfológicas, os patamares são identificados como áreas de média fragilidade, com valor 3 e as áreas de Cânion são identificadas como áreas de fragilidade alta, de valor 5 . Nesse caso considerou-se que as maiores inclinações potencializam a ocorrência de processos erosivos e movimentos de massa.

Quanto ao potencial de fragilidade propiciado pela vegetação, as áreas ocupadas com mata e cerrado tiveram a fragilidade classificada como baixa, com valor 1. Já as áreas com vegetação em regeneração possuem fragilidade baixa - média, com valor 2 . As áreas com cultura anual e pastagem melhorada apresentam fragilidade média com valor 3 . As áreas de pastagem são de fragilidade média alta, valor 4. Já as áreas ocupadas com hortifrutigranjeiros possuem fragilidade alta com valor 5 . Nesse caso considera-se que a maior cobertura vegetal propicia a proteção à superfície, e que a maior proximidade com as condições naturais incorporam maior proteção em relação às áreas que sofreram atuação antrópica.

Foi estabelecido que a classe de fragilidade baixa possui valores entre 4 e 5 , já a classe de fragilidade baixa - média possui valores entre 6 e 7, a classe de fragilidade média possui valores entre 8 e 9 , a classe de fragilidade media - alta possui valores entre 10 e 11 e a classe de fragilidade alta possui valores entre 12 e 13 (Tabela 1). 
Tabela 1. Análise Geral das Classes de Fragilidade da Bacia Hidrográfica do Córrego Pindaíba.

\begin{tabular}{ccccc}
\hline Unidade Geológica & Unidade Geomorfológica & Uso da Terra & Valor & $\begin{array}{c}\text { Classe de } \\
\text { Fragilidade }\end{array}$ \\
\hline Formação Marilia & Patamares & Mata & 5 & Baixa \\
Formação Marilia & Patamares & Vegetação em & 6 & Baixa - média \\
Formação Marilia & Regeneração & 7 & Baixa - média \\
Formação Marilia & Patamares & Pastagem Melhorada & 7 & Baixa - média \\
Formação Marilia & Cânion & Mata & 7 & Baixa - média \\
Embasamento Cristalino & Cânion & Cerrado & 7 & Baixa - média \\
Formação Serra Geral & Patamares & Mata & 6 & Baixa - média \\
Formação Serra Geral & Patamares & Mata & 7 & Baixa - média \\
Formação Marilia & Patamares & Vegetação em & Regeneração & Média \\
Formação Marilia & Patamares & Pastagem & 8 & Média \\
Formação Serra Geral & Patamares & Hortifrutigranjeiros & 9 & Média \\
Formação Serra Geral & Patamares & Pastagem Melhorada & 8 & Média \\
Formação Marilia & Patamares & Pastagem & 9 & Média \\
Formação Marilia & Cânion & Veg. em Regeneração & 8 & Média \\
Embasamento Cristalino & Cânion & Cultura Anual & 9 & Média \\
Formação Marilia & Patamares & Vegetação em & 9 & Média \\
Formação Marilia & Cânion & Regeneração & 9 & Pastagem Melhorada \\
Formação Marilia & Cânion & Pastagem & 10 & Média - alta \\
Formaçâo Serra Geal & Cânion & Hortifrutigranjeiros & 11 & Média - alta \\
\hline For Olivén & Patamares & Hortifrutigranjeiros & 10 & Média-Alta \\
\hline
\end{tabular}

Fonte: Oliveira (2006).

Para se chegar ao resultado final das classes de fragilidade existentes na bacia foram realizados cruzamentos entre todas as unidades e, posteriormente, a somatória dos valores atribuídos a essas unidades. Dessa forma, identificaram-se quatro classes de fragilidade na bacia hidrográfica do córrego Pindaíba (Figura 8).

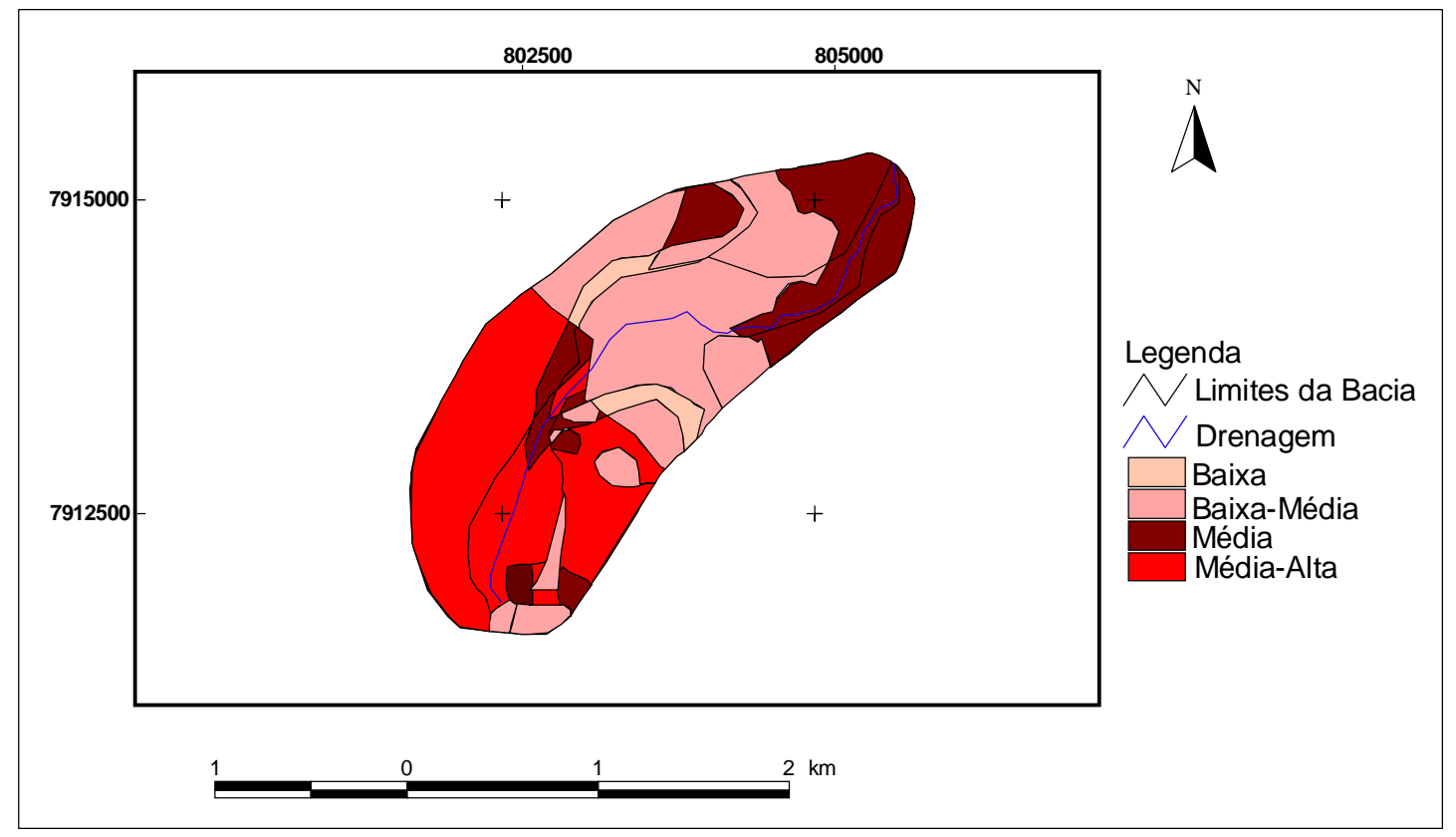

Figura 8. Fragilidade do Relevo da Bacia Hidrográfica do Córrego Pindaíba.

Autor: Oliveira (2006). 
A bacia hidrográfica do córrego Pindaíba apresenta cenários diferentes de degradação. Os agentes responsáveis por essa degradação partem de ações isoladas, que, em conjunto provocam impactos maiores, alterando a configuração natural da bacia.

A área das nascentes devem sofrer um processo de adequação às normas ambientais, como indica o parágrafo II do artigo $3^{\circ}$ do Código Florestal Brasileiro (Lei 4.771/65) (Brasil, 1965), que considera Área de Preservação Permanente o raio mínimo de 50 metros de largura que circunda as nascentes e olhos d'água, ainda que intermitentes. Além de serem cercadas para garantir a recuperação, essa área deve ser reflorestada com espécies nativas para que a cobertura vegetal seja retomada, e assim atue como um freio natural que impeça a compactação do solo, bem como a erosão pluvial, e ainda proteja as margens do córrego, evitando o assoreamento e garantindo a preservação desse curso d'água. As espécies podem ser conseguidas no Horto Florestal da Secretaria de Meio Ambiente da Prefeitura Municipal de Uberlândia, gratuitamente.

Um outro problema comum em toda a extensão da bacia são os represamentos e os desvios no curso do córrego para irrigação das lavouras. Esse fato pode ser considerado o mais relevante causador de degradação na bacia, uma vez que modifica a vazão natural do córrego. Cada propriedade deve utilizar a água de forma sustentável, respeitando o regime natural do córrego. Isso inclui a retomada do curso normal do córrego, reduzindo o número de barragens ao longo do canal.

A bacia hidrográfica do córrego Pindaíba deve ser explorada de acordo com suas potencialidades e sua capacidade de uso, visando a um constante equilíbrio do meio natural em detrimento das atividades antrópicas.

Várias ações devem ser realizadas para que o córrego se mantenha preservado. Porém tais ações devem ser tomadas e realizadas em conjunto por todos aqueles que utilizam a bacia, uma vez que é do interesse de todos preservá-la.

Conforme previsto no parágrafo IX do artigo $2^{\circ}$ do Comitê da Bacia Hidrográfica do Rio Araguari (Minas Gerais, 1998), sugere-se a criação do Comitê da Bacia Hidrográfica do Córrego Pindaíba, que contará com representantes do poder público, usuários da bacia e interessados, que serão responsáveis pela criação de projetos para a utilização sustentável da bacia, a fiscalização e aplicação da legislação vigente.

\section{CONCLUSÕES}

Este diagnóstico ambiental procurou compreender a dinâmica da bacia hidrográfica do córrego Pindaíba pelos processos naturais e das ações antrópicas. Salienta-se que as intervenções humanas são responsáveis pelo alto nível de alteração e degradação do meio natural. Em diferentes pontos da bacia, o uso do solo e os impactos por ele gerados são os mesmos.

A identificação das áreas com maior fragilidade do relevo indica que devem ser feitas alterações no uso da terra, adequando os tipos de cultura à morfologia da área. Assim, a bacia hidrográfica do córrego Pindaíba necessita de um planejamento que abranja não só os recursos naturais, mas também que inclua as necessidades de seus moradores.

Nos patamares, sugere-se a inserção das culturas consideradas com média, média-alta e alta fragilidade, como cultura anual, pastagem melhorada, pastagem e hortifrutigranjeiros devido também à feição geológica em que essa unidade está inserida. Nas áreas de cânion devido às formas mais aguçadas, sugere-se para o uso da terra mata e cerrado, que são consideradas de baixa e baixa-média fragilidade. As pequenas áreas atualmente ocupadas por 
pastagem e hortifrutigranjeiros nessa feição geomorfológica devem ser destinadas a áreas onde a vegetação natural possa se regenerar.

\section{REFERÊNCIAS}

AB'SABER, Aziz Nacib. Os domínios de natureza no Brasil: potencialidades paisagísticas. São Paulo: Ateliê Editorial, 2003. 160p.

ATEHORTÚA. M. R. Análise comparativa da geomorfológica, solos e uso da terra nos Municípios de Puerto López (Colômbia) e Uberlândia (Brasil). 2004. 180f. Dissertação (Mestrado em Geografia) - Instituto de Geografia, Universidade Federal de Uberlândia, Uberlândia. 2004.

BACCARO.C. A. D. Estudos geomorfológicos do Município de Uberlândia. Revista Sociedade e Natureza, Uberlândia, n. 1, v.1. p. 17-21, junho 1989.

BACCARO, C. A. D.; MEDEIROS, S. M.; FERREIRA, I. L.; RODRIGUES, S. C. Mapeamento geomorfológico da Bacia do Rio Araguari. In: LIMA, S. C; SANTOS, R. J. (Orgs.) Gestão ambiental da Bacia do Rio Araguari: rumo ao desenvolvimento sustentável. Uberlândia: Universidade Federal de Uberlândia, Instituto de Geografia. Brasília: CNPq, 2004. p. 1-20.

BOTELHO, R. G. M. Planejamento ambiental em microbacia hidrográfica. In: GUERRA, Antônio José Teixeira; CUNHA, Sandra Baptista. (Orgs.). Erosão e conservação de solos: conceitos temas e aplicações. Rio de Janeiro: Bertrand Brasil, 1995. p. 269-293.

BOTELHO R. G. M.; SILVA, A. S. da. Bacia hidrográfica e qualidade ambiental. In: VITTE, Antonio Carlos; GUERRA, Antonio José Teixeira. Reflexões sobre a geografia física no Brasil. Rio de Janeiro: Bertrand Brasil, 2004. p. 153-188.

BRASIL. Lei 4.771, de 15 de setembro de 1965. Institui o Novo Código Florestal. Disponível em: < http://www.planalto.gov.br/CCIVIL/LEIS/L4771.htm>. Acesso em: junho 2007.

MINAS GERAIS. Decreto 39.912 de 22 de Setembro de 1998. Institui o Comitê de Bacia Hidrográfica do Rio Araguari. Disponível em: <http://aguas.igam.mg.gov.br/ 2008nacbh/comites/cbhpn2/decreto.pdf> Acesso em: junho 2007.

BRASIL. Decreto 39.912 de 22 de Setembro de 1998. Institui o Comitê de Bacia Hidrográfica do Rio Araguari.

CONSÓRCIO CAPIM BRANCO ENERGIA. Planos de controle ambiental AHE Capim Branco I. Monitoramento do uso e ocupação do solo, cobertura vegetal e fontes de degradação dos recursos hídricos - Relatório de conclusão da fase II (Mapeamento simultâneo às obras). Araguari: CCBE, set. 2005. 57 p.

GIFFONI, S. N.; ROSA, R. Mapeamento dos remanescentes da cobertura vegetal natural do Município de Uberlândia no ano de 2002. In: SIMPÓSIO BRASILEIRO DE SENSORIAMENTO REMOTO, 13., 21 a 26 de abril de 2007, Florianópolis. Anais... São José dos Campos: INPE, 2007. p. 1679-1686. 1 CD -ROM

GUERRA, A. J. T.;CUNHA, S. B. Degradação ambiental. In: GUERRA, A. J. T.;CUNHA, S. B. (orgs.). Geomorfologia e meio ambiente. Rio de janeiro: Bertrand Brasil, 1996. 
INSTITUTO BRASILEIRO DE GEOGRAFIA E ESTATÍSTICA. Cartas topográficas. Folhas SE 22-Z-B-VI-4 NE; SE 22-Z-B-VI-4 NO. Rio de Janeiro: IBGE, 1984. 1 mapa. Escala 1:25.000.

KAWAKUBO, F. S.; MORATO, R. G.; CAMPOS, K. C.; LUCHUARI, A.; ROSS, J. L. S. Caracterização empírica da fragilidade ambiental utilizando geoprocessamento. In: SIMPÓSIO BRASILEIRO DE SENSORIAMENTO REMOTO, 12., 16 a 21 de abril 2005, Goiânia. Anais... São José dos Campos: INPE, 2005. p. 2203-2210. 1 CD -ROM

MARQUES, A. S. Ciência geomorfológica. In: CUNHA, Sandra Baptista da; GUERRA, Antonio José Teixeira. Geomorfologia, uma atualização de bases e conceitos. Rio de Janeiro: Bertrand Brasil, 2001. p. 23-50.

NISHIYAMA, L. Geologia do Município de Uberlândia e áreas adjacentes. Revista Sociedade e Natureza, Uberlândia, n. 1, v. 1, p. 9-16, junho 1989.

NISHIYAMA, L. Procedimentos de mapeamento geotécnico como base para análises e avaliações ambientais do meio, em escala 1:100000: aplicação no município de Uberlândia - MG. 1998. Tese (Doutoramento em Geotécnica) - FFLCH, Universidade de São Paulo, São Paulo, 1998.

OLIVEIRA, P. C. A. de. Diagnóstico ambiental e análise da fragilidade do relevo da Bacia Hidrográfica do Córrego Pindaíba, Uberlândia - Minas Gerais. 2006. Monografia (Graduação em Geografia) - Instituto de Geografia, Universidade Federal de Uberlândia, Uberlândia, 2006.

PREFEITURA MUNICIPAL DE UBERLÂNDIA. Banco de dados integrados - BDI. 2007. Disponível em: <http://www3.uberlandia.mg.gov.br/home_bdi.php>. Acesso em: jun. 2007.

RODRIGUES, Silvio Carlos. Análise da fragilidade do relevo: abordagem empíricoexperimental. Revista Sociedade e Natureza, Uberlândia, n. 12, p. 167-189, jan./jun. 2000.

ROSS, J. L. S. Geomorfologia: ambiente e planejamento. 5. ed. São Paulo: Contexto, 1990. $84 \mathrm{p}$.

ROSS, J. L. S. Análise empírica da fragilidade dos ambientes naturais e antropizados. Revista do Depto de Geografia - FFLCH-USP, São Paulo, n. 8, p. 63-74, 1994.

SANTOS, R. F. dos. Planejamento ambiental: teoria e prática. São Paulo: Oficina de Textos, 2004. 184 p.

SILVA, E. M.; ASSUNÇÃO, W. L. O Clima na cidade de Uberlândia. Revista Sociedade e Natureza, Uberlândia, n. 30, v. 16, p. 91-107, jun. 2004.

SPÖRL, C.; ROSS, J. L. S. Análise comparativa a fragilidade ambiental com aplicação de três modelos. Revista GEOUSP - Espaço e Tempo, São Paulo, n. 15, p.39-49, 2004.

TRICART, J. Ecodinâmica. Rio de Janeiro: FIBGE / SUPREN, 1977. 